\title{
PREVALENCE OF NEEDLE STICK INJURIES AMONG HEALTH CARE PROVIDERS.
}

\author{
Najma Rais \& Hafiza Mubashira Jamil
}

Dow University of Health Science

Corresponding Author: najmarais@hotmail.com

\begin{abstract}
Percutaneous exposure to contaminated needle sticks and other sharps is an occupational hazard to HCWS that causes morbidity and mortality from infections with blood borne pathogens. This study was conducted to see the prevalence of needle stick injuries among health care providers at Civil Hospital Karachi (CHK).The objective is to study the prevalence of NSI among HCWs, the most frequent reason of injury, common causative equipment, and affected site of hand. It is an Prospective Observational cross sectional study at CHK in its 3 units including 100 participants. Study was conducted from 2nd Jan 2012 to 28th Feb 2012. Result shows that a large percentage (77\%) of HCWs reported having had one or more NSIs in their career. While $23 \%$ did not report NSI in their career.(40.3\%) NSIs occurred during use of the needle. Greater part of injuries reported due to disposable syringes (45/77 or 58.4\%). Finger was affected by NSIs, in $72.7 \%$ cases.Our study concluded that the occurrence of NSI was found to be very frequent among HCWs in our setup. Poor compliances to universal precautions is a risk factor for sharp injuries. Some circumstances such as pressure of work and time constraint was a contributing factor. NSIs could reduce with the use of safer designed equipment. The promotion of adequate working conditions and Training programs regarding safety precautions on ongoing basis is very essential for future control of NSIs among health care workers at Hospitals.
\end{abstract}

\section{KEYWORDS}

Health care workers, needle stick injuries, mortality, morbidity

\section{INTRODUCTION}

A needle stick injury is a percutaneous wound, occurs due to needle point as well as due to other sharp instruments. Most common in those people, who are handling needles in the medical settings. These injuries are occupational hazard in medical community. Needle stick injuries are the most common health care workers issue(Atenstaed ,2007).These injuries are not only causing health consequences but also cause emotional distress in health care workers which results in missed workdays and directly affects the health care services and resources (Sharma , 2010). Most of the injuries occur due to three basic devices i.e. IV equipment, sutures needles and hollow bore needles. But for surgical personals and for perioperative nurses, sutures needles are most common equipment that causes injuries (Edwin, 2000).Other most important causes of NSI are two-handed recapping, the unsafe collection and disposal of sharps waste (Berguer, 2004). During surgery percutaneous injuries occur regularly due to which patient are at high risk of infection with blood borne pathogens (Tokars, 1992).The majority of gloves tears have an unknown mechanism that leads sharp injury, causes to transmit Blood borne pathogens in operating room (James, 1991). Needles should not recap after use because it can lead to an injury to health care providers (Marketa, 1990). Needle stick injuries are responsible to transmit blood-borne diseases through the passage of the hepatitis B virus (HBV), the hepatitis C virus (HCV), and the Human Immunodeficiency Virus (HIV), the virus which causes AIDS (William, 1988).

Each year worldwide around 66,000 HBV, 16,000 HCV and 1,000 HIV infections were estimated to occur among HCWs - mostly in developing countries - due to their occupational exposure to percutaneous injuries. Work-related infections are responsible for about $37 \%$ of $\mathrm{HBV}$ infections, $39 \%$ of $\mathrm{HCV}$ infections and $4.4 \%$ of HIV infections among HCWs worldwide (Prüss-Üstün, 2005).

At least 1,000 health care workers are estimated to contract serious infections annually from needle stick and sharps injuries (International Health Care Worker Safety Center, 1999).

Poor compliances to universal precautions, is a risk factor for sharp injuries and it doubles the risk to get an injury (A.Jacob, F.Dick. 2010). The exact reason for under reporting is unclear. Workload pressure and time constraints are likely to cause needle stick injuries (Clarke SP, Aiken LH, 2002).

2 million Needle stick injuries are reported in health care providers every year but these are only the reported cases and about $40-70 \%$ cases of needle stick injuries are unreported in developing countries (Habib, H 2011).According to World Health Organization (WHO) regional classification. Pakistan comes in Eastern Mediterranean Region D (EMR D). Unfortunately this region has the highest rate of needle stick injuries as compared to the entire world(Prüss-Üstün 2005).

As most of the cases of NSIs are under reported in developing countries and Pakistan is one of these countries, so this study aims to collect data of NSIs among HCWs in a tertiary care hospital of Karachi city and to determine factors, circumstances, affected sites, most common equipment and other important reasons of NSIs among health care providers.

\section{PARTICIPANTS AND METHOD}

This was a cross sectional study among health care workers on details of NSIs at Civil Hospital Karachi in its 3 units: 100 participants: ( including resident doctors, interns, nursing staff, nursing students, and technicians, medical students, surgeons, Anesthetists and Technologists, HCWs of OTC, HCWs of General surgery unit and HCWs of Emergency department). Study was conducted from 2nd Jan 2012 to 28th Feb 2012. Permission for carrying out the study was taken in advance. . Data collection involved the simple interviewing technique using a questionnaire that was filled by the interviewer. The questionnaire was constructed in English and Urdu. The data was analyzed using SPSS version 16. Frequencies were calculated for all variables which gave the numbers and percentages of responses of all variables.

RESULTS 


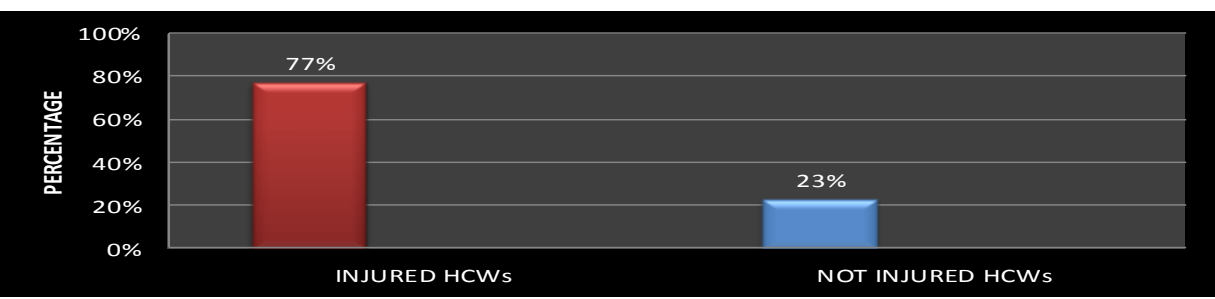

Fig 1-1 Graph shows percentage of injured and not injured health care workers

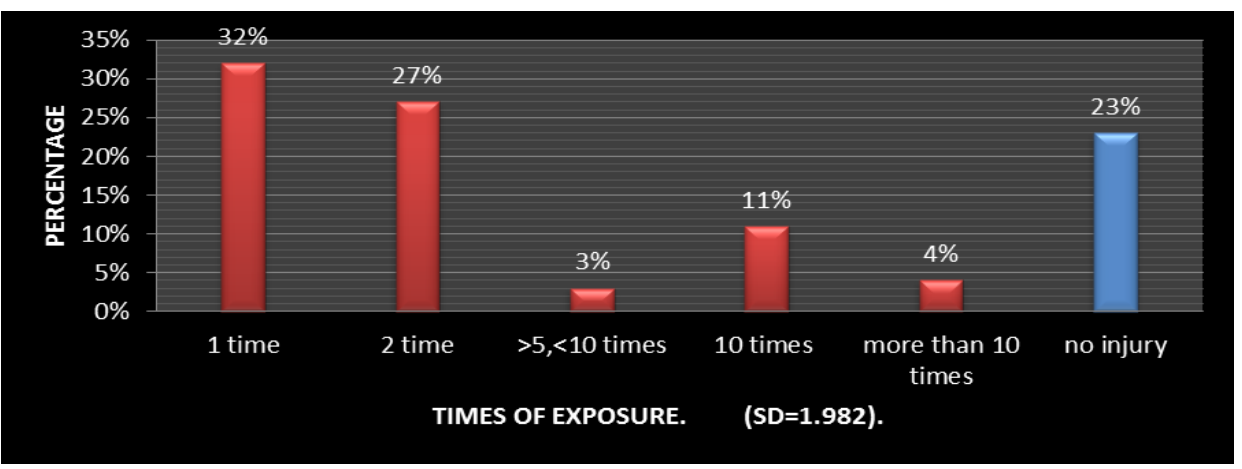

Fig 1-2 Graph shows percentage of times of exposure to needle stick injuries among HCWs

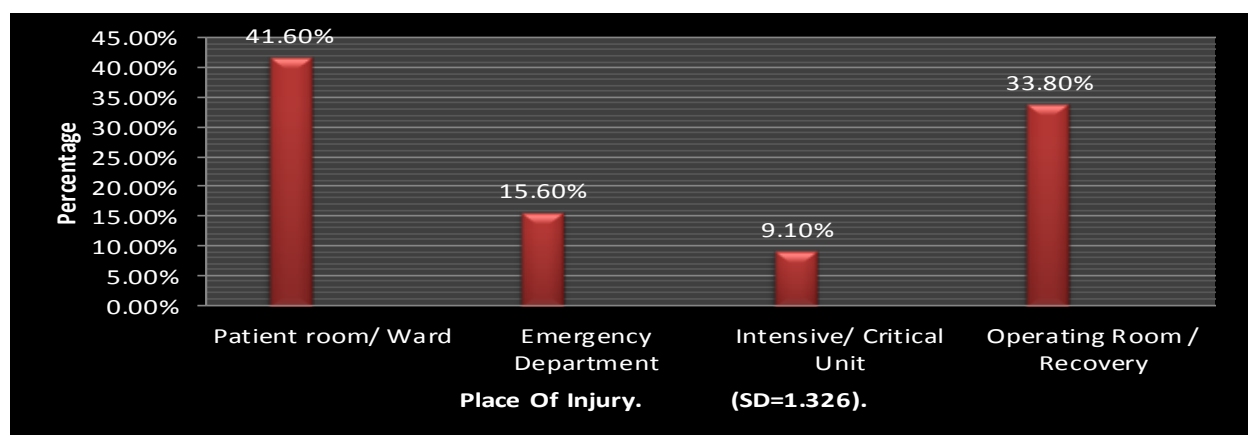

Fig 1-3 Graph shows percentage of NSIs took place at different departments.

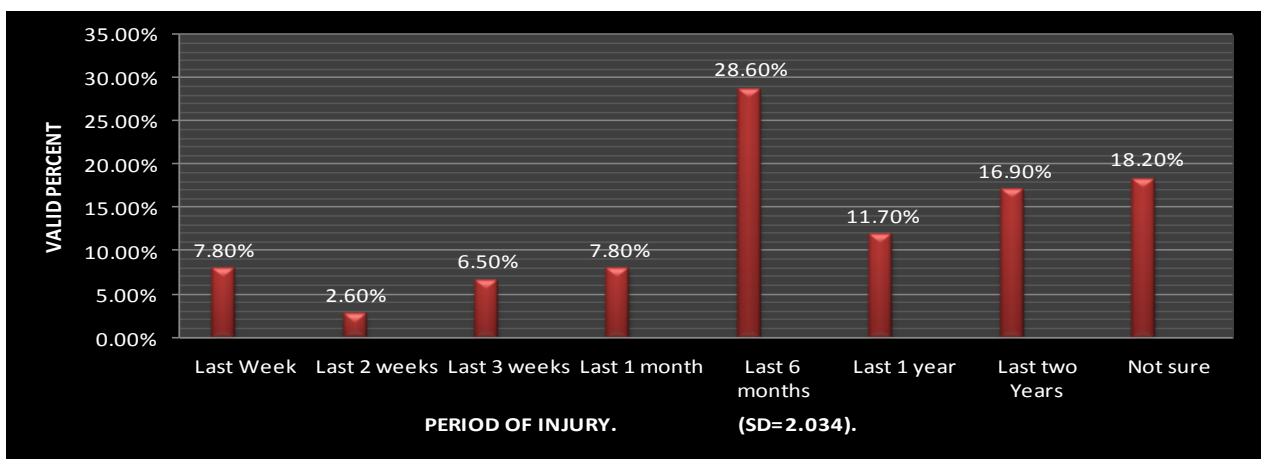

Fig 1-4 Graph shows percentage of NSIs in different time period.

DESIGNATION OF HEALTH CARE WORKERS 


\begin{tabular}{|c|c|c|c|c|c|}
\hline Designation & No. of Participants & $\begin{array}{l}\text { No. of } \\
\text { injured } \\
\text { HCW's }\end{array}$ & $\begin{array}{l}\text { No. of not } \\
\text { injured } \\
\text { HCW's }\end{array}$ & $\begin{array}{c}\% \text { of Injured } \\
\text { HCW's }\end{array}$ & $\begin{array}{l}\text { \%of not } \\
\text { injured } \\
\text { HCW"S }\end{array}$ \\
\hline Doctor & 48 & 42 & 6 & $87.5 \%$ & $12.5 \%$ \\
\hline Nurse & 13 & 10 & 3 & $76.9 \%$ & $23.0 \%$ \\
\hline Medical Student & 9 & 6 & 3 & $66.6 \%$ & $33.3 \%$ \\
\hline Nursing Student & 12 & 6 & 6 & $50 \%$ & $50 \%$ \\
\hline Paramedics & 5 & 2 & 3 & $40 \%$ & $60 \%$ \\
\hline Technicians & 8 & 7 & 1 & $87.5 \%$ & $12.5 \%$ \\
\hline Technologist & 5 & 4 & 1 & $80 \%$ & $20 \%$ \\
\hline "Total NO. OF PARTICIPANTS & 100 & 77 & 23 & $777 \%$ & $23 \%$ \\
\hline
\end{tabular}

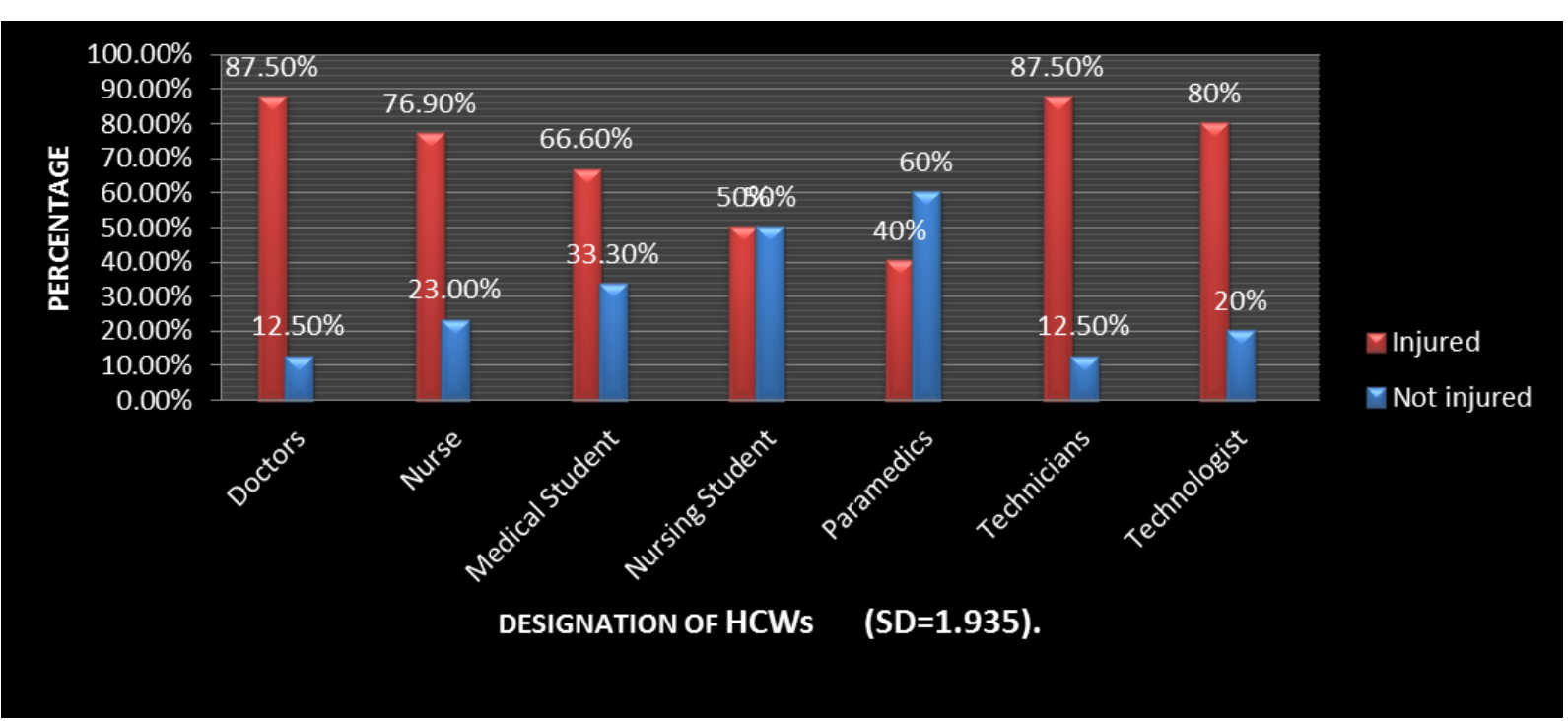

Fig 1-5 Graph shows the percentage of NSIs among medical and allied health care workers.

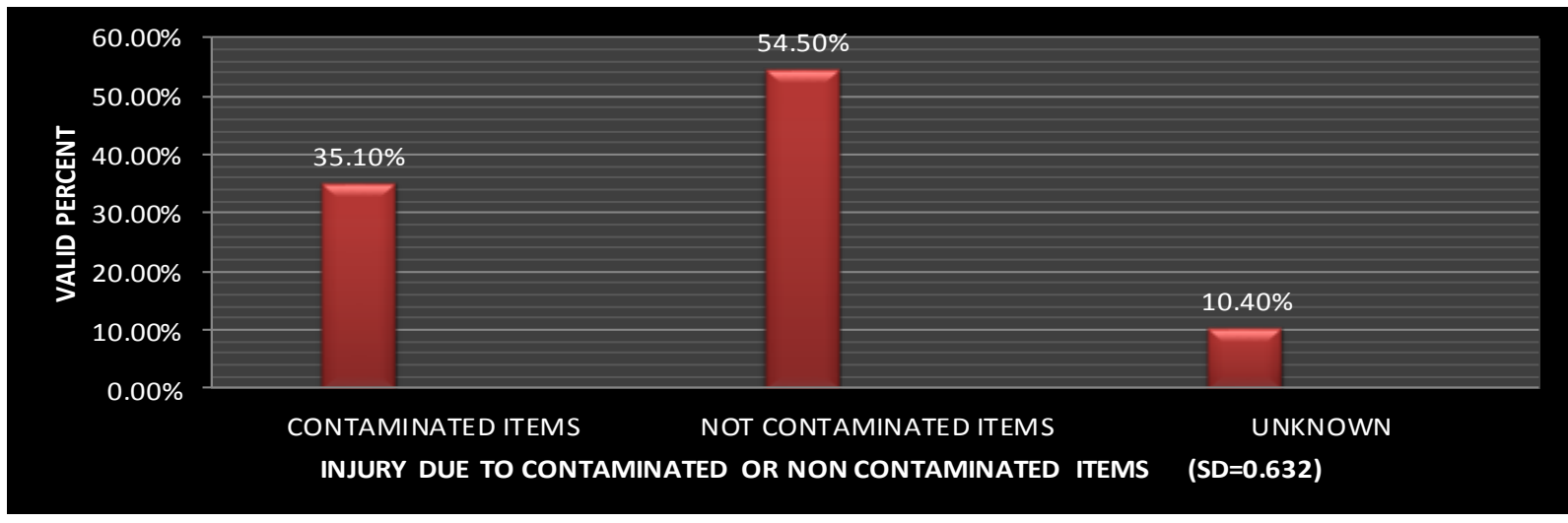

Fig 1-6 Graph shows percentage of injury due to contaminated and non-contaminated items.

CAUSES OF NEEDLE STICK INJURIES 


\begin{tabular}{ccc}
\hline CAUSE & FREQUENCY & $\begin{array}{c}\text { VALID } \\
\text { PERCENT }\end{array}$ \\
During use of needle & $40.3 \%$ \\
Disassembling device or equipment & 31 & $7.8 \%$ \\
In preparation for reuse of reusable instruments. & 6 & $2.6 \%$ \\
While recapping a used needle & 2 & $19.5 \%$ \\
Withdrawing a needle from rubber or other resistance & 15 & $9.1 \%$ \\
Other after use, before disposal & 7 & $3.9 \%$ \\
While putting the item into the disposal container & 3 & $1.3 \%$ \\
Restraining Patient & 1 & $5.2 \%$ \\
Device left on floor, table, bed or other inappropriate place & 4 & $2.6 \%$ \\
Due to pressure of work & 2 & $2.6 \%$ \\
Due to collision with other person & 2 & $4.2 \%$ \\
\hline Total & 77 & $100 \%$ \\
\hline
\end{tabular}

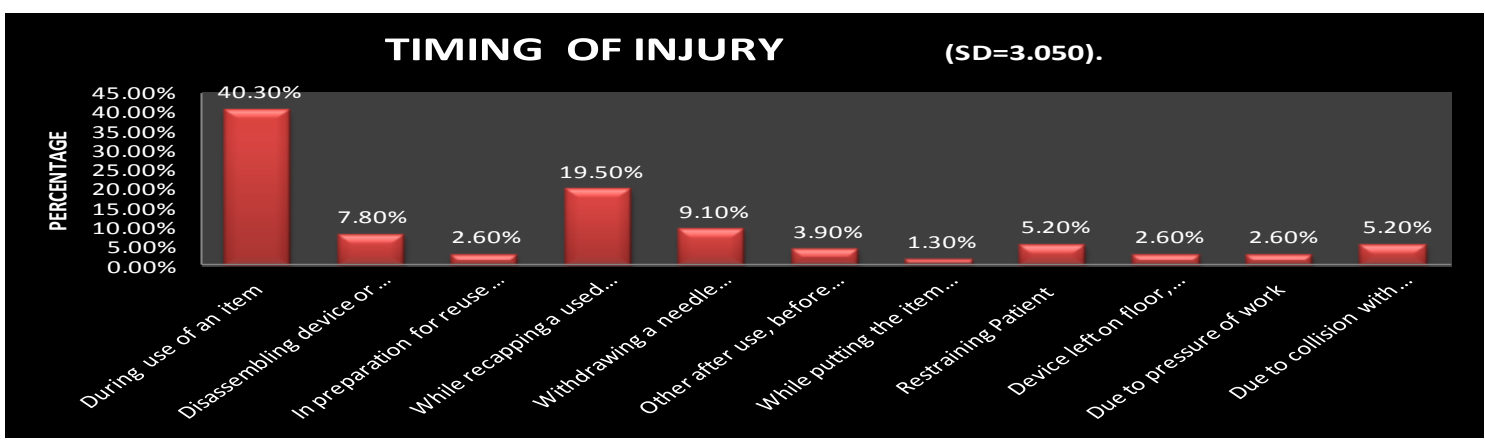

Fig 1-7 Graph shows the percentage of various circumstances, due to which needle stick injury had occurred

NSIS DUE TO DIFFERENT ITEMS:

\begin{tabular}{ccc} 
ITEMS & FREQUENCY & VALID PERCENTAGE \\
\hline Disposable syringe & 45 & $58.4 \%$ \\
Prefilled cartridge syringe & 3 & $3.9 \%$ \\
Needle on IV tubing & 2 & $2.6 \%$ \\
IV catheter & 3 & $3.9 \%$ \\
Needle / holder vacuum tube blood collection & $2.6 \%$ \\
Unattached hypodermic needle & 1 & $1.3 \%$ \\
Needle unknown type & $2.6 \%$ \\
Suture needle & 19 & $24.7 \%$ \\
\hline \hline Total & 77 & $100 \%$ \\
\hline
\end{tabular}

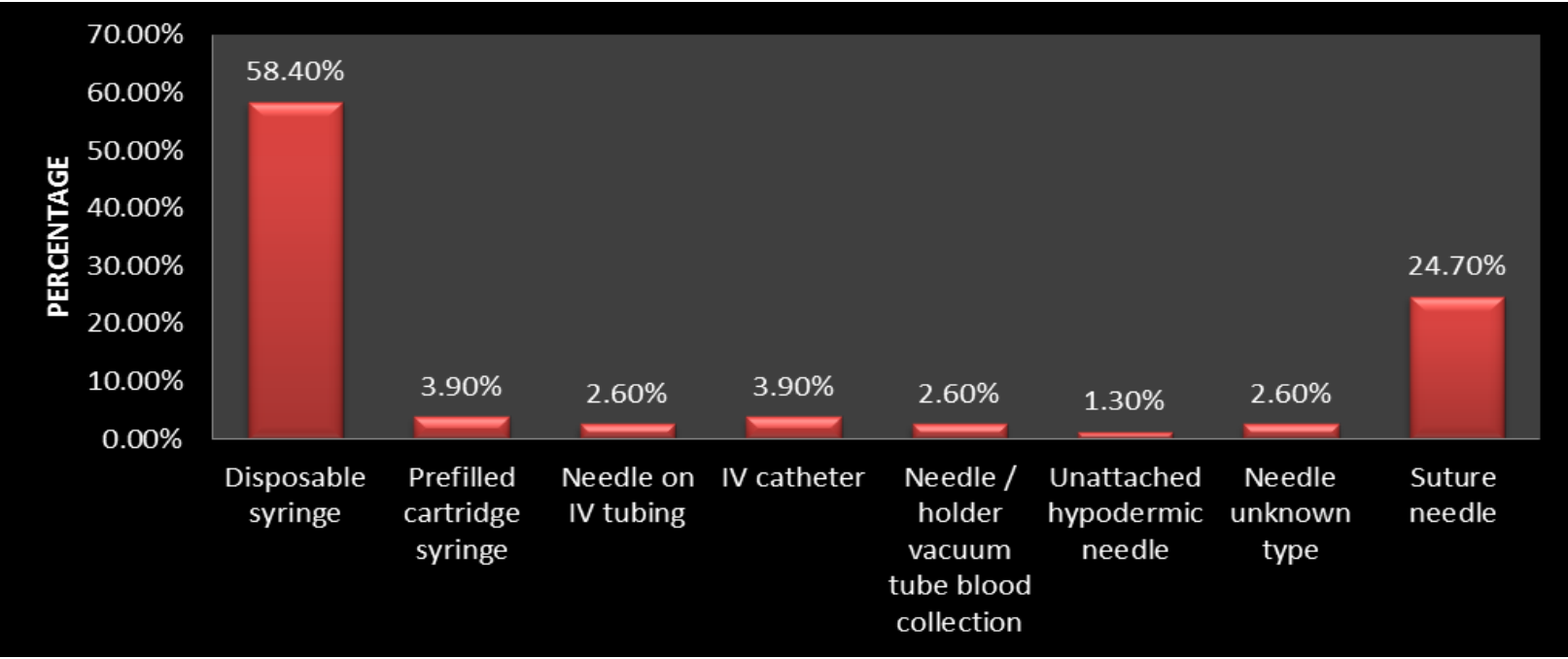

Fig 1-8 this graph shows the percentage of NSIs, occurred due to different items. 


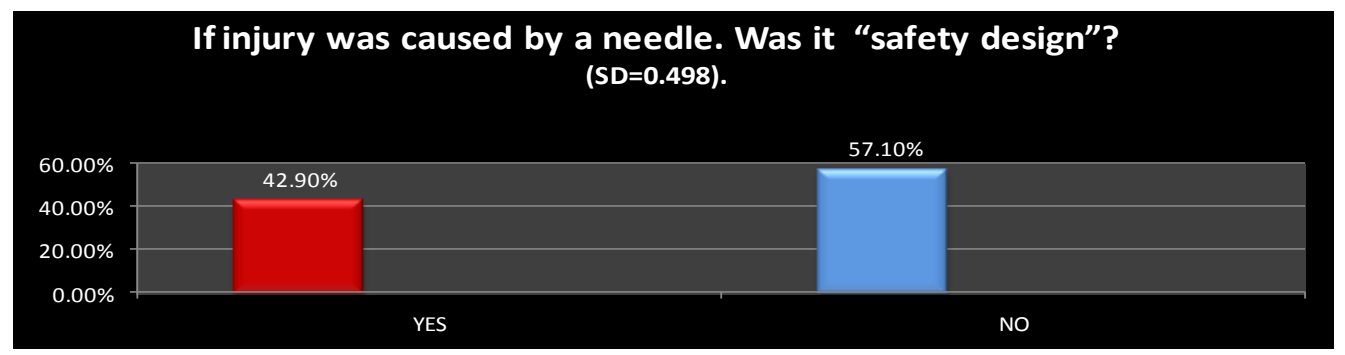

Fig 1-9 Graph shows percentage of NSIs, caused by a safety designed needle or not. LOCATION OF INJURY:

\begin{tabular}{ccc|}
\hline LOCATION & FREQUENCY & VALID PERCENTAGE \\
ARM & 1 & $1.3 \%$ \\
FACE/ HEAD & 2 & $2.6 \%$ \\
FINGER & 56 & $72.7 \%$ \\
RIGHT HAND & 9 & $11.7 \%$ \\
LEFT HAND & 9 & $11.7 \%$ \\
\hline \hline Total & 77 & $100 \%$ \\
\hline
\end{tabular}

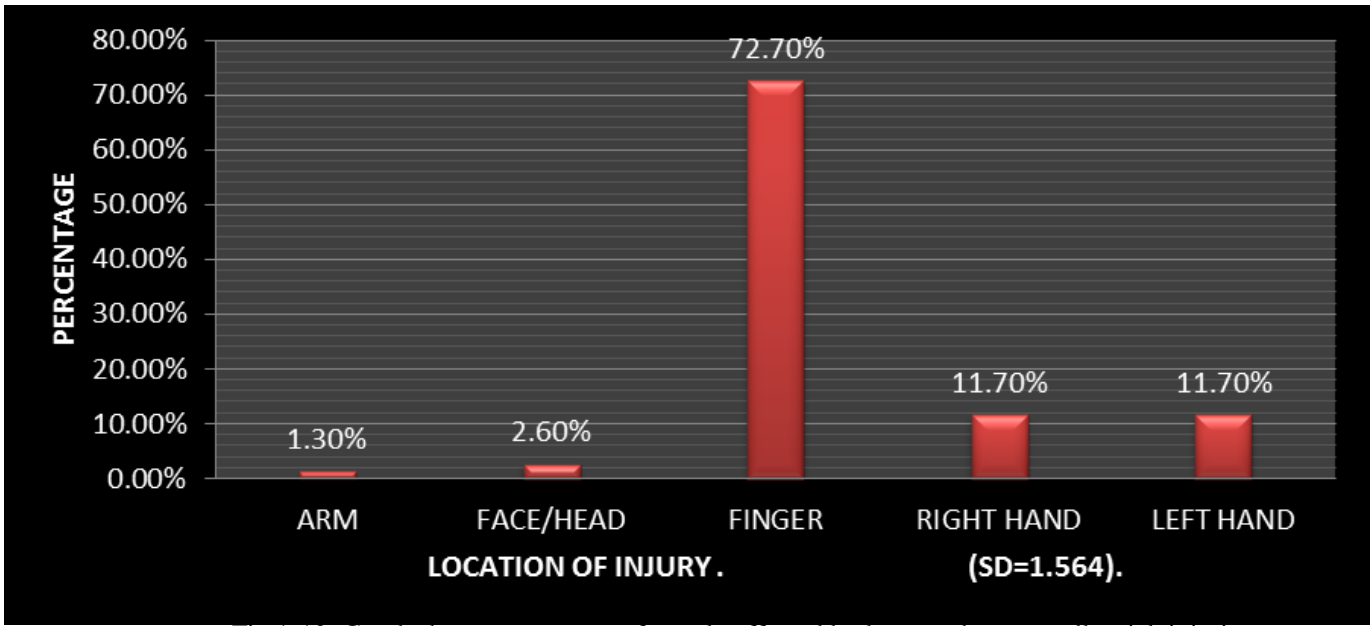

Fig 1-10: Graph shows percentage of mostly affected body parts due to needle stick injuries.

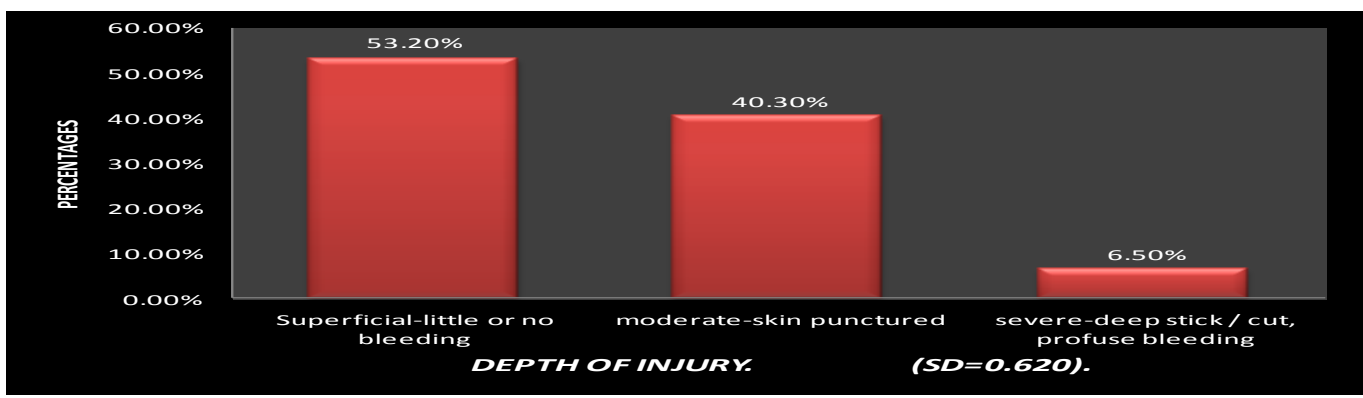

Fig 1-10: Graph shows percentage of depth of injury.

RECAPPING OF NEEDLE: $\mathrm{SD}=0.327$

RECAPPING OF NEEDLE $\quad$ FREQUENCY $\quad$ VALID PERCENTAGE

\begin{tabular}{ccc} 
YES & 88 & $88.0 \%$ \\
NO & 12 & $12.0 \%$ \\
\hline \hline Total & 100 & $100 \%$ \\
\hline
\end{tabular}

TECHNIQUE OF RECAPPING:

$(\mathrm{SD}=0.496)$. 


\begin{tabular}{ccc}
\hline Techniques of recapping & FREQUENCY & VALID PERCENT \\
One hand technique & 51 & $58 \%$ \\
Two hands technique & 37 & $42 \%$ \\
\hline \hline Total & 88 & $100 \%$ \\
\hline \hline
\end{tabular}

\section{DISCUSSION}

In our study, we found that, a large number (77\%) of HCWs reported NSIs during their career in civil hospital Karachi. A study conducted in 2011 at Alexinderia Hospital reported that more than two-thirds of HCWs $(438,67.9 \%)$ had sustained at least 1 NSI in the previous 12 months (Hanafi, 2011). Lower prevalence of NSIs was reported among HCWs in 2 Malaysian teaching hospitals (31.6\% and52.9\% respectively) (Ng YW, 2007). A recent study reported that, large percentage $(79.5 \%)$ of HCWs having had one or more NSIs in their career at Delhi (India) (Sharma , 2010). We found that, 32\% HCWS reported 1 time NSI, 27\% reported 2 times, $3 \%$ reported $>5$ times < 10 times, $11 \%$ HCW's reported 10 times, $4 \% \mathrm{HCWs}$ reported more than 10 times NSIs in their career.

In our study $77 \%$ of HCWs had NSI, the highest number of NSIs (41.6\%), reported at Patient room / Ward (15.6\%) NSIs reported at Emergency Department, ( 9.10\%) at Intensive Care / Critical Unit and (33.80\% ) NSIs reported at Operating Room/ Recovery. While another study conducted in 2010 at Buraidah central Hospital reported $42.5 \%$ NSIs occurred in hospitals wards, $19.2 \%$ in the accident and emergency department, $16.4 \%$ in the operation theater and $13.7 \%$ in the Intensive Care unit (Buraidah, Al-Qassim, 2005). However only $16.4 \%$ of the injuries were reported in the operation theater in Buraidah central Hospital, as compare to a high rate of $33.8 \%$ in our study. One explanation is that in civil hospital, a large number of patients come for surgical treatment and pressure of work and time constraint responsible for this huge numbers of injuries.

The incidence of NSIs was $28.6 \%$ (22/77) during Last 6 months. During last two years $16.90 \%$ ( $13 / 77$ ) HCWs had NSIs, during last 1 year $11.70 \%$ (9/77), last 1 month 7.8\% (6/77), Last 3 weeks $6.50 \%$ ( 5/77), Last 2 weeks $2.6 \%$ (2/77), Last week $7.8 \%$ ( 6/77) NSIs were reported by HCWs during our research period i.e. (from 2 nd Jan, 2012 to 28th Feb 2012. ). We found maximum number of NSIs during last 6 months, while $18.20 \%(14 / 77) \mathrm{HCWs}$ were not sure about their time period of injury. Underreporting of NSI is a common problem in our healthcare facilities. Although hospital employees are requested to report such accidents, a lot of injuries go unreported. Injuries recorded through standard occupational reporting systems may underestimate the true injury rate, as much as 10-fold (Elder, 2006).

Among 100 Participants: 48 Doctors participated in our study: $87.5 \%$ had NSI, 13 Nurses participated in our study: $76.9 \%$ had NSI.9 Medical students participated in our study: $66.6 \%$ had NSI, 12 Nursing Students participated in our study: 50\% had NSI, While 50\% did not report NSIs in their career. 5 paramedics participated in our study: $40 \%$ had NSI, 8 technicians participated in our study: $87.5 \%$ had NSI, 8 technologists participated in our study: $80 \%$ had NSI, While 20\% did not report NSIs in their career. In our study we found that highest number of NSIs was sustained by senior doctors and paramedics followed by technologists with $80 \%$ and registered nurses with $76.9 \%$ NSIs. A study reported $(28.4 \%)$ NSIs among nurses, (9.1\%) nursing interns, $(21.6 \%)$ doctors, $(15.9 \%)$ medical interns and (8.1\%) NSIs among technicians during July 2006-June 2007 in a tertiary care hospital (Jayanth, 2009). Another study reported, that doctors were the most frequent victims $(64.7 \%)$, followed by waste disposal staff (25.5\%) and Nurses (7.8\%) (Prakash, 2012).

During this study $77 \%$ of HCWs reported NSIs. In $54.5 \%$ (42/77) cases injury occurred due to non- contaminated items, $35.10 \%$ (27/77) of the injuries were reported due to contaminated items. While $10.4 \%$ (8/77) HCWs were not sure about items contamination or noncontamination at the time of injury. However very high number $(90 \%)$ of the NSIs reported with contaminated instruments in U N Mehta institute of cardiology and research Centre Ahmadabad [
Mihir, G,(2010)], as compare to a low rate of $35.10 \%$ in our study. Information was also elicited regarding the timing of the injury. In 31 $(40.3 \%)$ the injury occurred during use of the needle, (15 or $19.5 \%)$ reported during recapping a used needle, and $7(9.1 \%)$ during Withdrawing a needle from rubber or other resistance. 3.9\% NSIs reported after use, before disposal of needle, and 1.3\% NSIs were reported by HCWs when putting the item into the disposal container. In 2010 another study reported that, In 75 (29.4\%) the injury occurred during use of the needle, with the greater part of injuries (167 or $65.5 \%$ ) occurring after use but before disposal, and 13 (5.1\%) during disposal of the needle (Sharma, 2010).Another study reported an important finding that a majority of the injuries occurred not during use itself, but rather during the handling between use and its disposal (Ebrahimi, 2007). We found that, the rate of injury, during disassembling device or equipment was $7.8 \%$. During preparation for reuse of reusable instruments, the rate of NSAIs was 2.6\%.Due to restraining Patient $5.2 \%$ NSIs were reported by HCWs. Proper disposal of needles is very important, because improper disposal may cause an injury. In this study we found that $2.6 \% \mathrm{HCW}$ 's had a NSI due to device that left on floor, table, bed or other inappropriate place. Due to pressure of work $2.6 \%$ and due to collision with other person $5.2 \%$ NSIs reported during our study.

In this study, Greater part of injuries reported due to disposable syringes $(45 / 77$ or $58.4 \%)$, suture needles caused (19/77 or $24.7 \%)$ NSIs, while Pre filled cartridge syringe and IV catheter caused (3 / 77 or $3.9 \%$ ) NSIs and Needle on IV tubing, Needle / holder vacuum tube blood collection and Needle of unknown type caused respectively ( $2 / 77$ or $2.6 \%$ ) NSIs and Unattached hypodermic needle caused $(1 / 77$ or $1.3 \%)$ NSIs ( $\mathrm{SD}=4.753)$.Another study, majority (178 or $69.5 \%$ ) of the NSI were from a hollow-bore type of needle, while $30.5 \%$ incidents of injury were caused by solid-bore needle (Sharma, 2010). Another study proved that hollow bore needles caused $47.8 \%$ of injuries, $25.4 \%$ occurred with suture needles and $19.4 \%$ with intravenous cannulas (Foster,2010).

A study proved that, an average $34 \%$ of all needle stick injuries (NSIs) could have been avoided by the use of safety devices.( Evaluating the kind of activity under which the NSI occurred) (Wicker, 2008). Now manufactures have started to introduce safety designed needles in order to reduce NSIs. But still 42.9\% (33/77) NSIs were caused by a safety designed needle. While $57.10 \%$ victim HCWs were not using a safety designed needle at the time of injury $(\mathrm{SD}=0.498)$.A study reported that safety devices are available for $35.1 \%$ of needle stick injuries sustained (Wicker, 2008).

We found that in $72.7 \%$ cases mostly finger was affected by an injury. While right and left hand was affected by NSIs respectively in $11.7 \%$ cases. $(\mathrm{SD}=1.564)$.Out of 77 cases of NSIs, $53.20 \%$ (41/77) HCW s received superficial injuries , 40.30\% (31/77) HCWs received moderate -skin punctured, While 6.50\% (5/77) HCWs received severe-deep stick / cut, profuse bleeding.( $\mathrm{SD}=0.620)$. Another study reported an active bleeding from the wound in $62.9 \%$ of the NSI incidents (Sharma, 2010).

Several studies have shown recapping to be an important cause of NSI (Ebrahimi, 2007; Kermode, 2005 \& Prüss-Üstün, 2003). A study conducted at two hospitals in Jamaica, reported re-capping needles accounted for $21 \%$ of injuries (Fostern, 2010).It was found that $88 \%$ HCWs recap needles after use. While $19.5 \%$ NSIs reported during recapping of a used needle. Although training programs emphasize that recapping of needles after use is not to be done. A recent study have shown that $15.2 \%$ and $11.3 \%$ of $\mathrm{HCW}$ reported that they recapped a needle using the one-handed method and the two-handed method, respectively(Kakizaki, 2011).we found that $58 \%$ of HCWs recap a needle using the one-handed method and $42 \%$ of HCWs recap a needle using the two-handed method. Several of the HCWs had not 
been wearing gloves at the time of their injury, although wearing gloves is known to be an important line of defense against NSIs .Most $(84.4 \%)$ of the injuries were admitted to be because of error by self (Askarian, 2006). Another study have shown that (27.3\%) of HCWs had not been wearing gloves at the time of the incident. Staff nurses (44.7\%), senior residents (28.8\%) and lab technicians (32.3\%), were found to be most likely not to be wearing gloves (Sharma, 2010). Sharp injuries are major cause of transmission of Hep B \& C virus and human immunodeficiency virus among HCWs (Guo,1999) so proper vaccination is very important to reduce the risk of transmission of these fatal viruses. In our study $88 \%$ of HCWs completed vaccination course against $\mathrm{HepB}$, while $12 \% \mathrm{HCWs}$ were not vaccinated against hepB. Another study reported that $81.9 \%$ of HCWs were immunized with HBV vaccine (Sharma,2012).

\section{CONCLUSION}

The occurrence of NSI was found to be very frequent among HCWs in our setup. . Poor compliances to universal precautions are a risk factor for sharp injuries. Some practices like recapping of needles was contributing factor to NSIs. Some circumstances such as pressure of work and time constraint was a contributing factor. NSIs could reduce with the use of safer designed equipment. The promotion of adequate working conditions and Training programs regarding safety precautions on ongoing basis is very essential for future control of NSIs among health care workers at Hospitals.

\section{ACKNOWLEGEMENT}

Dr. Syed Sarwat, MD Director DIMT. Dr Masroor Afridi Research Consultant DIMT.Ms Shagufta and Ms Saima, Lecturer DIMT.

\section{REFERENCES}

- Adegboye, A. A., Moss, G. B., Soyinka, F., \& Kreiss, J. K. (1994). The epidemiology of needlestick and sharp instrument accidents in a Nigerian hospital. Infection control and hospital epidemiology, 27-31.

- Askarian, M., \& Malekmakan, L. (2006). The prevalence of needle stick injuries in medical, dental, nursing and midwifery students at the university teaching hospitals of Shiraz, Iran. Indian Journal of Medical Sciences, 60(6), 227.

- Atenstaedt, R. L., Payne, S., Roberts, R. J., Russell, I. T., Russell, D., \& Edwards, R. T. (2007). Needle-stick injuries in primary care in Wales. Journal of public health, 29(4), 434-440.

- Berguer, R., \& Heller, P. J. (2004). Preventing sharps injuries in the operating room. Journal of the American College of Surgeons, 199(3), 462-467.

- Buraidah, A. Q. (2005). Epidemiology of needlestick injuries among health care workers in a secondary care hospital in Saudi Arabia. Ann Saudi Med, 25(3), 233-238.

- Chicago Sharma, A., Gur, R., \& Bhalla, P. (2012). Study on prevalence of needle stick injury among health care workers in a tertiary care hospital in New Delhi: A two-year review. Indian Journal of Public Health, 56(1), 101

- Clarke, S. P., Sloane, D. M., \& Aiken, L. H. (2002). Effects of hospital staffing and organizational climate on needlestick injuries to nurses. American Journal of Public Health, 92(7), 1115-1119.

- Ebrahimi, H., \& Khosravi, A. (2007). Needlestick injuries among nurses. Journal of research in health sciences, 7(2), 56-62.

- Edwin A.Mcconnel RN, PhD (2000). Needle Stick Injuries among Health Care Providers. Association of Operating Room Nurses.

- Elder, A., \& Paterson, C. (2006). Sharps injuries in UK health care: a review of injury rates, viral transmission and potential efficacy of safety devices. Occupational medicine, 56(8), 566-574.; 56:566-74.

- Foster, T. M. (2010). "Prevalence of needle stick injuries and other high risk exposures among healthcare workers in Jamaica." West Indian Medical Journal, 59(2), 153-158

- Guo, Y. L., Shiao, J., Chuang, Y. C., \& Huang, K. Y. (1999). Needlestick and sharps injuries among health-care workers in Taiwan. Epidemiology and infection, 259-265.
- Habib, H., Khan, E. A., \& Aziz, A. (2011). Prevalence and Factors Associated with eedle Stick Injuries among Registered urses in Public Sector Tertiary Care Hospitals of Pakistan.

- Hanafi, M. I., Mohamed, A. M., Kassem, M. S., \& Shawki, M. (2011). Needlestick injuries among health care workers of University of Alexandria Hospitals. EMHJ, 17(1).

- Jacob, A., Newson-Smith, M., Murphy, E., Steiner, M., \& Dick, F. (2010). Sharps injuries among health care workers in the United Arab Emirates.Occupational medicine, 60(5), 395-397.

- James, G., Wright, M.D., David, F., Ransohoff, M.D. (1991). Mechanism of Glove Tears and Sharp Injuries among Surgical Persons. JAMA: the journal of the American Medical Association.

- Jayanth, S. T., Kirupakaran, H., Brahmadathan, K. N., Gnanaraj, L., \& Kang, G. (2009). Needle stick injuries in a tertiary care hospital. Indian journal of medical microbiology, 27(1), 44.

- Kakizaki, (2011). Needlestick and sharps injuries among health care workers at public tertiary hospitals in an urban community in Mongolia. BMC research notes, 4(1), 184

- Kermode, M., Jolley, D., Langkham, B., Thomas, M. S., \& Crofts, N. (2005). Occupational exposure to blood and risk of blood borne virus infection among health care workers in rural north Indian health care settings. American journal of infection control, 33(1), 34-41.

- Leisure, M. K., Moore, D. M., Schwartzman, J. D., Hayden, G. F., \& Donowitz, L. G. (1990). Changing the needle when inoculating blood cultures. JAMA: the journal of the American Medical Association, 264(16), 2111-2112.

- Merritt, W. T. (1988). How to Avoid Needle Stick Injury. JAMA. The Journal of the American Medical Association, 259(3), 353-354.

- Mihir, G., Parul, P., Sunil, N., HK, M., Rakesh, S., Dharmesh, D., \& Patel, R. K. (2010). Needle stick and sharp instruments injuries among health care providers at cardiology Institute, Ahmedabad. National Journal, 1(2), 114.

- Ng, Y.W., Hassim, I.N. (2007).NSI among medical personnel in Accident and Emergency Department of two teaching hospitals". Medical Journal of Malaysia. (62), 9-12.

- Pournaras, S., Tsakris, A., Mandraveli, K., Faitatzidou, A., Douboyas, J., \& Tourkantonist, A. (1999). Reported needlestick and sharp injuries among health care workers in a Greek general hospital. Occupational Medicine, 49(7), 423-426.

- Prakash, K. P., \& Patel, K. (2012). Epidemiology of Needle-Stick Injuries in Mangalore. Journal of Evolution of Medical and Dental Sciences, 1(3), 128.

- Prüss-Üstün, A., Rapiti, E., \& Hutin, Y. (2003). Sharps injuries. Global burden of disease from sharps injuries to health-care workers. Geneva, WHO. (WHO Environmental Burden of Disease Series, No. 3

- Prüss-Üstün, A., Rapiti, E., \& Hutin, Y. (2005). Estimation of the global burden of disease attributable to contaminated sharps injuries among health-care workers. American journal of industrial medicine, 48(6), 482-490.

- S.Pournaras ,A.Tourkantonist .(1994). Reported Needle Stick and Sharp injuries among Health Care Workers in a Greek General Hospital, Occup Med.

- Sharma, R., Rasania, S. K., Verma, A., \& Singh, S. (2010). Study of prevalence and response to needle stick injuries among health care workers in a tertiary care hospital in Delhi, India. Indian journal of community medicine: official publication of Indian Association of Preventive \& Social Medicine, 35(1), 74.

- Tokars, J. I., Bell, D. M., Culver, D. H., Marcus, R., Mendelson, M. H., Sloan, E. P, \& Martone, W. J. (1992). Percutaneous injuries during surgical procedures. JAMA: the journal of the American Medical Association, 267(21), 2899-2904.

- Wicker, Sabine. (2008). Prevalence and prevention of needle stick injuries among health care workers in a German university hospital." International archives of occupational and environmental health, 81(3), 347-354. 